\title{
Da Invisibilidade à Participação: A Expressão da Criança em Disputas de Guarda
}

\author{
From Invisibility to Participation: \\ The Expression of Children in Custody Disputes
}

Marcia Regina Ribeiro dos Santos \& Liana Fortunato Costa

Universidade de Brasília, Brasília, Brasil

\begin{abstract}
Resumo: Este artigo é parte de uma pesquisa qualitativa e visa analisar como a expressão da criança sobre sua percepção, durante o processo de disputa de guarda e regulamentação de visita, pode significar a possibilidade de a decisão judicial ser mais assertiva em relação ao que importa no atendimento aos seus interesses. Participaram 11 crianças entre 8 e 11 anos de idade, de nove famílias que estavam sob avaliação psicossocial por determinação do juiz. Os resultados revelaram que a criança tem clareza do significado de sua participação no contexto judicial, quer ser ouvida e ter sua opinião considerada e respeitada. Além disso, a criança reconhece ter autonomia para informar o seu ponto de vista e admite depender dos adultos nas tomadas de decisão no que considera ser melhor para ela.
\end{abstract}

Palavras-chave: expressão da criança, contexto de disputa de guarda, decisão judicial.
Abstract: This article is part of a qualitative study and seeks to analyze how the child's expression of his or her perception, during custody dispute processes and the establishment of visitation schedules, may result in court rulings being more assertive with regard to meeting the child's interests. Eleven children aged between 8 and 11, from nine families under court-ordered psychosocial assessment, participated in the study. The results show that children were aware of the meaning of their participation in the judicial context, that they wanted to be heard, and have their opinions considered and respected. In addition, the children also acknowledged that they were free to express their points of view and admitted depending on adults when it comes to deciding about what is best for them.

Keywords: child's expression, custody dispute context, court ruling.

Contato: M. R. Ribeiro dos Santos. SHIN QI 7 Conj. 7 Casa 5, Lago Norte, 71515-070, Brasília DF, Brasil. Correio electrônico: marciarrsantos@gmail.com

Como citar: Ribeiro dos Santos, M. R. \& Fortunato Costa, L. (2015). Da invisibilidade à participação: A expressão da criança em disputas de guarda. Revista de Psicología, 24(2), 1-15. 


\section{Introdução}

Este artigo tem origem em uma pesquisa qualitativa mais ampla, que foi realizada em contexto de Justiça, e objetiva conhecer a percepção da criança sobre o processo de disputa de guarda, durante a realização da avaliação psicossocial.

No Brasil, o princípio do melhor interesse da criança, estabelecido pela Convenção sobre os Direitos da Criança, passou a ser constitucional e infraconstitucional (Constituição Federal de 1988, Art. 227, caput, e Estatuto da Criança e do Adolescente, Art. $4^{\circ}$, caput, e Art. $5^{\circ}$ ), desde que a Assembleia Geral das Nações Unidas aprovou a citada convenção em 20 de novembro de 1989 (em vigor desde 2 de setembro de 1990). Sua inclusão objetivou nortear a ação das instituições públicas em atender aos direitos da criança dependente de adultos responsáveis para auxiliá-la a desenvolver-se. Além de ser aplicado pelo Estado, o referido princípio deve ser incorporado e cumprido pela família e, também, pela sociedade (Kreuz, 2012). Esse princípio é considerado meta-jurídico e precisa da contribuição de outras áreas da ciência, pois requer entendimentos de vários interessados envolvidos: a própria criança, seus pais, outros familiares, profissionais da psiquiatria, serviço social, psicologia, juízes, dentre outros como contribuição na obtenção de subsídios para a decisão (Monteiro, 2010). Entretanto, pela natureza das opiniões científicas, não há certezas absolutas, sendo necessário esclarecer quanto às inerentes limitações pela particularidade de cada família que recorre a esse contexto (Santa Rosa, Almeida, \& Corte-Real, 2014).

A tomada de decisão do juiz envolve o atendimento ao princípio do melhor interesse da criança, o qual implica o direito de ela ser ouvida sobre todos os assuntos que lhe são referentes, conforme o artigo 12 da Convenção sobre os Direitos da Criança (Fundo das Nações Unidas para a Infância, [Unicef], 1990). Desse modo, a expressão da percepção da criança pode subsidiar a decisão judicial (Skjørten, 2013), o que significa buscar a preservação do seu bem-estar, observando-se a qualidade de sua interação com a família, respeitando-se suas necessidades individuais, que são específicas e únicas, a saúde mental e física de todos os envolvidos, e considerando-se sua idade e grau de maturidade (Fuhrmann \& Zibbel, 2012; Monteiro, 2010; Unicef, 1990).

No contexto da Justiça, as decisões que envolvem criança estão entre as mais difíceis de serem tomadas (Ackerman, 2006; Fuhrmann \& Zibbell, 2012; Graham \& Fitzgerald, 2010; Grisso, 2003; Huss, 2009; Patel \& Choate, 2014; Santa Rosa, Corte-Real, \& Vieira, 2013; Santa Rosa et al., 2014). Assim, na Justiça de família, o melhor interesse da criança deve ser analisado em cada caso e o julgador, ao decidir com base nesse critério, está imbuído de subjetividade (Huss, 2009; Skjørten, 2013), pois considera a qualidade do afeto na interação dos pais com a criança e a competência parental na promoção do seu desenvolvimento (Agulhas \& Anciães, 2014; Santa Rosa et al., 2013; Stahl, 2011).

Entretanto, a implicação da criança nesse contexto significa um direito e não uma obrigação (Santa Rosa et al., 2013). Em processos de guarda e regulamentação de visita, algumas crianças nem sempre querem ser incluídas nas tomadas de decisão, outras estão ansiosas para oferecer suas contribuições. A criança reconhece a diferença entre ter uma voz e ter que fazer uma escolha quando os adultos a interpelam (Birnbaum \& Saini, 2012; Cardoso \& Costa, 2014). Portanto, analisar a expressão da criança significa contemplar a au- 
tonomia de sua vontade, que engloba: a) o desenvolvimento da capacidade crítica, b) considerar a criança como um sujeito de direitos e que tem algo a dizer, c) considerar diferentes padrões relacionais de sua família e como suas preocupações podem ser afetadas pelo contexto em que está inserida (Cashmore \& Parkinson, 2008). Ao mesmo tempo, os pontos de vista e as perspectivas das crianças são, por vezes, ambíguos e nem sempre transmitem relatos facilmente discerníveis, ou contam histórias consistentes com o que os adultos querem ouvir. Os adultos nem sempre são claros sobre o objetivo da participação das crianças, confundindo-as entre permitir dizer o que pensam e terem de expressar a opinião sobre o que querem (Agulhas \& Anciães, 2014; Graham \& Fitzgerald, 2010; Santa Rosa et al., 2013; Santa Rosa et al., 2014).

No âmbito nacional brasileiro, a discussão sobre a participação da criança na Justiça, a partir de sua voz, apresenta-se de modo crítico, ainda sem consenso e em processo de construção. O pano de fundo das discussões indica cuidado para não tornar a criança mero informante, evitando-se mantê-la na invisibilidade, mas aceitandoa como sujeito de direitos, destacando sua indivisibilidade e integralidade, na valorização do seu protagonismo por meio de políticas públicas inclusivas e de qualidade (Arantes, 2009). Brito, Ayres, e Amendola (2006) apontam que ouvir a criança seria para saber sua opinião sobre com quem deverá residir, como é a interação parental e como é tratada pelos pais. Ferreira (2008) questiona se o acatamento integral da vontade da criança é o caminho mais adequado no atendimento do seu melhor interesse, uma vez que ela tem sua voz permeada por motivações e efeitos da dialética familiar. Ribeiro (2010) afirma que os pais em intenso conflito na Justiça não priorizam as necessidades emocionais da criança, porque estão focados em si próprios. A pesquisa de Cardoso e Costa (2014) discute a disputa de guarda envolvendo avós e netos e faz referência à voz da criança, apontando preocupação em ouvir o que ela tem a dizer, enfatizando, sobretudo, que ela não quer se posicionar quanto à decisão, requerendo proteção para que um terceiro decida por ela.

$\mathrm{Na}$ esfera internacional, os estudos vêm se intensificando há mais de vinte anos e, cada vez mais, as investigações têm mostrado a relevância em ouvir a voz da criança, atentando-se para os seus diferentes pontos de vista e o contexto familiar em que está inserida (Birnbaum \& Saini, 2012; Cashmore \& Parkinson, 2008; Saywitz, Camparo, \& Romanoff, 2010). Enquanto algumas crianças esperam decidir, outras preferem apenas fornecer suas opiniões e preferências; há as que optam por manifestar-se quanto aos desajustes no processo de separação versus resiliência e adaptação à dinâmica das novas famílias; outras, ainda, precisam de uma casa como referência, diferentemente daquelas que necessitam relacionar-se com ambos os pais. O principal aspecto é considerar a voz da criança na tomada de decisão e não apenas seguir a perspectiva dela na crença de estar atendendo ao seu melhor interesse. É necessário considerar a tensão entre a sua participação e a sua proteção, evitando considerá-la como vítima dos desentendimentos entre os pais depois da separação. Ao se ouvir a criança, observa-se haver, na interação entre ela e seus pais, preferência ou rejeição com sentimento de ambivalência; reação de passividade e retraimento diante de situações de conflito ou se está triangulada (Agulhas \& Anciães, 2014; Birnbaum 
\& Saini, 2012; Cashmore, 2011; Cashmore \& Parkinson, 2008; Cashmore \& Parkinson, 2009; Ferreira, 2008; Pereira \& Matos, 2008; Saywitz et al., 2010; van Nijnatten \& Jongen, 2011). Sob essa ótica, a criança, ao participar da argumentação, reflexão e tomadas de decisão em conjunto, deixa de ser invisível, tornandose sujeito de direitos, tendo validado e respeitado o seu ponto de vista (Costa \& Miragem, 2012; Skjørten, 2013). Portanto, o essencial em se ouvir o conteúdo de sua fala é o significado de sua expressão, o reconhecimento como sujeito digno, que merece confiança no desenvolvimento de sua autonomia, na articulação entre seus mundos interno e externo (Cashmore, 2011; Costa, Penso, Legnani, \& Sudbrack, 2009; Minuchin, 1990; Minuchin \& Fishman, 1990; Minuchin, Nichols, \& Lee, 2009; Santa Rosa et al., 2013).

\section{Método}

A presente investigação pautou-se na pesquisa qualitativa, que utiliza a interpretação como fundamento (Bauer, Gaskell, \& Allum, 2010; Flick, 2009). Sem perder de vista as interações familiares, a pesquisa privilegiou a entrevista apenas com a criança. Assim, a análise parte do olhar que a criança traz do contexto familiar observado no momento da avaliação psicossocial durante a tramitação do processo de disputa de sua guarda e regulamentação de visita na Justiça.

\section{Contexto}

A pesquisa ocorreu no Tribunal de Justiça do Distrito Federal e Territórios (TJDFT/DF), Brasília, Brasil, onde há uma equipe composta por psicólogos e assistentes sociais que realiza estudo psicossocial com as famílias encaminhadas pelo juiz. Os atendimentos foram organizados por esses profissionais, com os diferentes subsistemas da família, incluindo o acolhimento individual da criança.

\section{Participantes}

O critério para a seleção dos casos foi a dinâmica familiar que evidenciou intenso conflito, crônico ou não, principalmente, entre o par parental (Johnston, Roseby, \& Kuehnle, 2009). Os participantes foram 11 crianças pertencentes a nove famílias que fizeram parte do estudo psicossocial, com idades que variaram entre 8 e 11 anos, conforme descrição na Tabela 1.

\section{Instrumentos}

Para a realização da entrevista foi utilizado um roteiro que procurou enfatizar as expressões da criança. Esse roteiro englobou os seguintes aspectos: o motivo de estar na Justiça, as histórias contadas sobre as suas percepções e vivências no contexto familiar e as concepções sobre a sua percepção representadas por meio de desenhos. Para tanto, pediu-se que, em uma folha em branco, a criança desenhasse as suas preocupações sobre o conflito familiar envolvendo a disputa de guarda. Em seguida, foi pedido que fizesse outro desenho, representando as soluções em relação às preocupações apontadas (Puviani, 2011). Para essa autora, o desenho torna visível o mundo interno que está obscuro, relacionando-o com o exterior na comunicação de emoções e sentimentos, tornando-o autorrevelação, integrando o verbal e o não verbal. 
Tabela 1

Dados das Crianças Participantes da Pesquisa e da Ação Judicial por Família

\begin{tabular}{|c|c|c|c|c|c|c|c|c|c|}
\hline \multirow[b]{2}{*}{ Família } & \multicolumn{5}{|c|}{ Dados da criança } & \multicolumn{4}{|c|}{ Ação judicial } \\
\hline & Nome & Idade & Sexo & $\begin{array}{c}\text { Ano } \\
\text { escolar }\end{array}$ & Reside com & Tipo da ação & $\begin{array}{l}\text { Movida } \\
\text { por }\end{array}$ & Contra & Motivo da ação \\
\hline \multirow[t]{2}{*}{$\mathrm{F} 1$} & P1 & 11 & $\mathrm{M}$ & $6^{\circ}$ & Pai e irmã de 13 anos & \multirow{2}{*}{$\begin{array}{l}\text { Reconhecimento e Disso- } \\
\text { lução de União Estável }\end{array}$} & \multirow[t]{2}{*}{ Pai } & \multirow[t]{2}{*}{ Mãe } & \multirow{2}{*}{$\begin{array}{l}\text { Violência interparental, uso abusivo de } \\
\text { álcool e negligência dos filhos. }\end{array}$} \\
\hline & $\mathrm{P} 2$ & 8 & M & $3^{\circ}$ & Mãe e irmã de 4 anos & & & & \\
\hline $\mathrm{F} 2$ & $\mathrm{P} 3$ & 9 & $\mathrm{~F}$ & $3^{\circ}$ & $\begin{array}{l}\text { Mãe e irmão de } 13 \\
\text { anos }\end{array}$ & Guarda e Responsabilidade & Mãe & Pai & $\begin{array}{l}\text { Mãe suspeita de abuso sexual da filha na } \\
\text { casa paterna por enteados. }\end{array}$ \\
\hline $\mathrm{F} 3$ & P4 & 10 & $\mathrm{~F}$ & $5^{\circ}$ & Mãe e avós maternos & Regulamentação de Visita & $\begin{array}{l}\text { Avós } \\
\text { paternos }\end{array}$ & Mãe & $\begin{array}{l}\text { Visitas do pai à filha suspensas judicial- } \\
\text { mente por abuso sexual comprovado. }\end{array}$ \\
\hline $\mathrm{F} 4$ & P5 & 9 & M & $3^{\circ}$ & $\begin{array}{l}\text { Mãe, companheiro e } \\
\text { um irmão unilateral } \\
\text { de } 6 \text { anos }\end{array}$ & Acordo de Guarda & $\begin{array}{l}\text { Avós } \\
\text { maternos, } \\
\text { mãe e pai }\end{array}$ & Não há & $\begin{array}{l}\text { Benefícios em plano de saúde e bolsa de } \\
\text { estudos. }\end{array}$ \\
\hline F5 & P6 & 8 & M & $2^{\circ}$ & $\begin{array}{l}\text { Mãe e irmã de } 14 \\
\text { anos }\end{array}$ & Regulamentação de Visita & $\begin{array}{c}\text { Avó } \\
\text { paterna }\end{array}$ & Mãe & $\begin{array}{l}\text { Conflitos sobre visitas que ocorriam antes e } \\
\text { se mantiveram depois do falecimento do } \\
\text { pai. }\end{array}$ \\
\hline F6 & P7 & 9 & M & $4^{\circ}$ & $\begin{array}{l}\text { Pai e companheira } \\
\text { dele }\end{array}$ & Regulamentação de Visita & Pai & Mãe & $\begin{array}{l}\text { Acusação de maus tratos físicos e psicoló- } \\
\text { gicos durante as visitas na casa materna. }\end{array}$ \\
\hline F7 & P8 & 10 & $\mathrm{~F}$ & $5^{\circ}$ & $\begin{array}{l}\text { Mãe, avó e tio mater- } \\
\text { no }\end{array}$ & Regulamentação de Visita & Mãe & Pai & $\begin{array}{l}\text { Pedido de suspensão das visitas por acusa- } \\
\text { ção de abuso sexual pelo pai e pedido de } \\
\text { guarda por negligência da mãe portadora de } \\
\text { esquizofrenia. }\end{array}$ \\
\hline \multirow[t]{2}{*}{$\mathrm{F} 8$} & P9 & 11 & M & $5^{\circ}$ & Pai e irmão de 9 anos & Modificação de Guarda & Pai & Mãe & Pedido dos filhos para morarem com o pai. \\
\hline & $\mathrm{P} 10$ & 9 & M & $3^{\circ}$ & $\begin{array}{l}\text { Pai e irmão de } 11 \\
\text { anos }\end{array}$ & & & & \\
\hline F9 & P11 & 9 & M & $3^{\circ}$ & Mãe & Modificação de Guarda & Pai & Mãe & $\begin{array}{l}\text { Proteção do filho contra a suspeita de maus } \\
\text { tratos perpetrados pela mãe. }\end{array}$ \\
\hline
\end{tabular}

Nota $: \mathrm{M}=$ Masculino; $\mathrm{F}=$ Feminino. 


\section{Procedimentos}

As informações foram coletadas durante a realização do estudo psicossocial, concomitante ao período em que as ações referentes à disputa de guarda, regulamentação de visita e modificação de cláusula (de guarda e de visita) foram tratadas, bem como a dissolução de união estável e divórcio litigioso que envolveu guarda e visitação dos participantes entrevistados. A coleta ocorreu durante os meses de novembro e dezembro de 2013. A entrevista para a obtenção das informações, com o objetivo de conhecer a percepção da criança, foi realizada somente na presença dela. As salas onde as entrevistas foram realizadas estavam equipadas com material lúdico (jogos e brinquedos), além de material de apoio, e as entrevistas tiveram a duração aproximada de 40 minutos e foram gravadas em áudio, e posteriormente transcritas. A gravação das falas reuniu o que foi dito pela criança, durante os diálogos estabelecidos com a pesquisadora, e também durante a confecção dos desenhos.

O conteúdo foi analisado na modalidade temática apontada por Minayo (2014). Essa proposta de análise de conteúdo segue um curso de leitura exaustiva, significação das falas contidas nos diálogos, compreensão da significação organizada em núcleos de sentido e, finalmente, interpretação do conteúdo dentro dos núcleos. Buscou-se privilegiar, no processo de interpretação, o significado da manifestação referente ao "contexto e às circunstâncias em que se dá" (Minayo, 2014, p. 202). Para tal, os diálogos foram codificados e categorizados em dois momentos diferentes. Primeiramente, por duas psicólogas com experiência de pesquisa e de atuação no contexto judicial, no que se refere às implicações constantes deste contexto. Em seguida, houve a discussão conjunta entre as pesquisadoras responsá- veis pela pesquisa e autoras deste texto, sobre o material analisado, com o fim de construção sintética dos temas, de forma ampliada. A síntese permitiu a organização em núcleos e a ampliação compôs a discussão e o aprofundamento dos temas. A composição dos núcleos se deu seguindo essa perspectiva com a escolha de títulos que identificassem, de pronto, as interpretações construídas.

\section{Cuidados Éticos}

O projeto foi submetido ao Comitê de Ética em Pesquisa, conforme resolução do Conselho Federal de Psicologia (CFP) 016/2000, incluindo o termo de compromisso assinado pelo responsável do Tribunal de Justiça, os Termos de Consentimento Livre e Esclarecido (TCLE) para o responsável da(s) criança(s) e o Termo de Assentimento, na forma oral, para as crianças.

\section{Resultados e Discussão}

A partir da análise das informações coletadas em relação à expressão da criança, destacaram-se três núcleos de sentido: a Justiça é que decide; o juiz é quem decide; o processo de reflexão.

\section{Núcleo 1. "Um Fórum é pra Decidir as Coisas": A Justiça é que Decide}

O material, que deu origem à discussão neste item, é proveniente da gravação dos diálogos com a pesquisadora. A maior parte das crianças, oito das 11 entrevistadas, evidenciou reconhecer e identificar a razão de estar naquele local. P1: "É pra decidir se eu fico com o meu pai ou com a minha mãe. Pra decidir as coisas". Como não é possível morar com ambos os pais, há o entendimento de que a decisão seria feita por um terceiro, o "juiz", que decidiria "as coisas", ainda que a criança se 
reconheça como parte integrante dessas "coisas". A literatura nessa área não destaca que a criança confia na decisão da Justiça, porém evidencia a necessidade da participação dela nos assuntos que lhe são pertinentes, de modo a ter o seu ponto de vista considerado nas tomadas de decisão (Birnbaum, Bala, \& Cyr, 2011). Além disso, a criança espera que o resultado seja, de algum modo, equilibrado, embora considere que os seus interesses podem não ser os mesmos dos seus pais (Cashmore \& Parkinson, 2008). Uma crítica possível cabe à Justiça, quando, na busca pelo melhor interesse da criança, pode intensificar o litígio e fortalecer a dependência de todos pela apreciação judicial (Fuhrmann \& Zibbel, 2012). A criança, ao aguardar a decisão da Justiça, evidencia reconhecer sua dependência dessa instância na garantia de sua proteção e bem-estar.

P10: "Pra decidir com quem a gente vai ficar...". P11: "Pra decidir quem vai ficar com a minha guarda". P3: "Eu sei que o meu pai tá brigando pela guarda da gente" [dela e dos irmãos]. A criança sabe que há um jogo entre o pai e a mãe, e a Justiça é que irá decidir. P5: "Eu tô aqui porque a minha vó [materna] vai pegá a minha guarda. (...) Porque eu pedi pra ela". A família atendeu ao seu pedido e ajuizou a ação de guarda. A família a ouviu e espera que o poder judicial também o faça. P2: "Para falar dessas coisas assim... de mãe e de pai". A Justiça representa um local no qual alguém irá escutá-la, confiando poder fazer "revelações" concernentes à mãe e ao pai. P6: "Eu não sei por que eu tô aqui direito. (...) quando alguém tenta disputar pela coisa que ela quer, aí não quer deixar a outra [ganhar], ela quer que ganha" [a disputa]. A criança não tem clareza sobre o motivo pelo qual está na Justiça, não conseguindo correlacionar sua presença na Justiça com a regulamentação de visitas requerida pela avó paterna contra a sua mãe. Entretanto, reconhece que há algo de impeditivo na interação entre elas e entende que será decidido fora do âmbito familiar, sendo que, inevitavelmente uma delas irá "ganhar" a disputa. É um direito da criança ser informada sobre o que está acontecendo em relação às mudanças que a envolvem e pronunciar-se, sentir-se motivada a fazê-lo, bem como ter o conhecimento das implicações de sua participação nesse contexto (Birnbaum et al., 2011; Birnbaum \& Saini, 2012; Byrnes, 2011). Dessa maneira, contribui para o desenvolvimento da autonomia da criança participar-lhe as mudanças que poderão ocorrer em sua vida e o envolvimento da Justiça em tomadas de decisões que lhe dizem respeito, pois ela é parte integrante e ativa na relação com a família e a Justiça.

Esse núcleo assinalou que a maior parte das crianças entrevistadas tinha conhecimento de que se tratava de contexto de decisão, e apontaram que quando encontram espaço favorável para contar sua história, elas o fazem, pois se sentem respeitadas em seus recursos emocionais para se manifestarem em assuntos dos quais fazem parte (Birnbaum et al., 2011). Além disso, indicaram que, se a conjuntura lhes for favorável e se a Justiça se dispuser a ampliar a valorização de sua expressão como sujeito de direitos (Costa et al., 2009), poderão tornar-se visíveis (Costa \& Miragem, 2012) na transitoriedade entre a autonomia e a interdependência com os adultos que estão como seus responsáveis (Minuchin, 1990; Minuchin \& Fishman, 1990; Minuchin et al., 2009).

Três crianças cujas expressões de falas contribuíram para a discussão neste núcleo estavam dependentes de uma decisão 
judicial que poderia beneficiá-las em relação à sua segurança e proteção, em virtude da presença de violência nas interações familiares. Tal condição impõe uma importância para o fato de o contexto judicial poder acolher o sofrimento advindo de suas incertezas e anseios por estarem em local e em companhia de pessoas com as quais se sintam seguras. $\mathrm{O}$ fato de a criança poder informar sobre o que ocorre na intimidade das relações em família, ainda mais em contexto decisório, constitui um elemento fundamental de restabelecimento da proteção. A participação da criança possibilita não apenas que ela avalie sobre as repercussões da decisão judicial em sua vida, mas também, contribui para decisões mais coerentes com as suas necessidades e para a viabilidade dos acordos judiciais (Santa Rosa et al., 2013).

\section{Núcleo 2. O "Bom Hábito": O Juiz é Quem Decide}

Neste núcleo, observou-se que das 11 crianças, cinco disseram que a disputa será decidida pelo juiz: P9, P2, P1, P11 e P6, sendo que outras três, P3, P4 e P10 antes de reconhecerem que a decisão é do juiz, apontaram a sua implicação no contexto de decisão. P10: "Se meu pai tiver um bom hábito, vai ficar com a gente!”. A criança sabe que a decisão será do juiz e acredita na determinação imposta por ele, valorizando a competência do julgador, que tem conhecimento e autoridade para decidir, mas duvida dos "hábitos do pai" e espera que o juiz possa avaliá-los (Santa Rosa et al., 2013). A expectativa da criança é de que, se o juiz concluir de modo favorável ao "bom hábito" paterno, a decisão vai beneficiá-la, pois ela quer ficar com o pai. É curiosa a preocupação da criança, sugerindo uma inversão hierárquica na relação com o pai (Minuchin, 1990), visto que ela e seu irmão é que estão atentos aos hábitos que regem a vida do responsável por eles. Esse processo teve seu prosseguimento quando o pai, sentindose encorajado com o pedido dos filhos, formalizou uma ação processual contra a mãe. A criança compreende a organização familiar e espera que suas demandas sejam valorizadas para sua proteção. Segundo Ausloos (1996), a família tem competência para gerir seus problemas, suas dificuldades, porém, em certas ocasiões, por não saber como utilizá-la, recorre a outras instâncias, fora do seu sistema, e ao buscar a Justiça, fornece os elementos, as informações pertinentes à tomada de decisão (Santa Rosa et al., 2013).

Outra fala que oferece ilustração na direção do reconhecimento do juiz como a pessoa que decide foi dado por P4: "Acho que o que eu tenho para fazer eu já fiz, falar que eu queria voltar a ver minha avó, meu avô, queria ir para a casa deles. Agora [é] só esperar mesmo a decisão do juiz". O desenho feito por essa participante é um exemplo de comunicação das perturbações vividas pela criança. Ao referir-se à saudade que sente da convivência com a avó, desenha uma casa colorida de marrom, reproduzindo a expressão da "agonia". A cor marrom representa a terra, elemento da natureza que indica acolhimento, repetindo a sensação que tinha nas ocasiões em que estava em visita aos avós. Há, ainda, uma carinha com destaque para a palavra tristeza, como a indicar sua incursão na sensação de saudade já manifestada. "Uma carinha triste são os olhos. Aí o nariz, e a boca triste". O desenho aponta uma ênfase na expressão de seus sentimentos, em relação à falta do convívio com os avós, a sua agonia, a sua perturbação e a dificuldade em verbalizar o que sente. $O$ segundo desenho, o da solução: "Eu, minha avó... nós duas... se vendo quando a gente quisesse... em um lugar feliz...", representando 
uma solução possível de ser alcançada. Essa criança foi vítima de abuso sexual perpetrado pelo pai, que já estava separado da ex-mulher e morava com a avó da criança. Essas circunstâncias fizeram que, em um processo anterior, a criança ficasse impedida de estar na casa dos avós. $\mathrm{Na}$ oportunidade de ser escutada durante o momento da pesquisa, a criança indica seu sofrimento pela ausência da convivência com os avós.

Este núcleo demonstrou que a criança é autônoma em expressar sua opinião, mas depende de um adulto que decida por ela, dando-lhe segurança e exercendo autoridade sobre ela, porque ainda transita entre autonomia e dependência (Andolfi, 1991; Minuchin, 1990; Minuchin \& Fishman, 1990). Sua expectativa é que possa dar sua opinião (autonomia), mesmo necessitando de proteção (dependência), com suas expressões mediadas por profissionais especializados (Byrnes, 2011; Cardoso \& Costa, 2014; Cashmore \& Parkinson, 2008). Assim sendo, as suas expressões serão transmitidas ao juiz pelos profissionais com conhecimento específico nessa área, pois o magistrado não tem o saber adequado sobre desenvolvimento infantil e nem sobre a dinâmica das interações familiares (Santa Rosa et al., 2013). Portanto, a criança, ao ser ouvida por profissional preparado para esse fim (Agulhas \& Anciães, 2014; Huss, 2009), sente-se segura, convicta de que seus pontos de vista, próprios e únicos, estão sendo incluídos na tomada de decisão, e que seus interesses estão sendo cuidados, diferenciando-os do discurso familiar conflituoso (Foot, 2011; Pereira \& Matos, 2011).

\section{Núcleo 3. "Pode Acontecer Isso?": O} Processo de Reflexão

Para a análise deste item, consideraram-se tanto as falas contidas nos diálogos com a entrevistadora como os desenhos. Este núcleo apontou que enquanto a criança aguarda a sentença do juiz ela faz reflexões a respeito de suas expectativas sobre a decisão. P10: "Que meu pai, ele é uma boa pessoa, cuida da gente e dá carinho". P4: "Dependendo do que o juiz decidir, pode [permitir as visitas]". P2: "Nós dois (ele e o irmão) [vamos] ficar com o meu pai e aquelas duas [irmãs] podem ficar com a minha mãe?". Essas falas foram expressas no momento dos diálogos entre a entrevistadora a as crianças, indicando que elas, além de pensarem reflexivamente sobre o problema, imaginam uma possível decisão judicial que possa ser dada a partir da valorização do que ela indicar. Mesmo que ela ainda se encontre em ambiguidade, com pensamentos contraditórios em razão do medo de ser abandonada (Agulhas \& Anciães, 2014; Graham \& Fitzgerald, 2010; Minuchin et al., 2009).

No desenho do problema, P7 se representa situada entre o pai e a mãe que tem uma sandália em sua mão. "Uma sandália, eu, é com essa daqui que ela (mãe) me bateu! E o meu pai também! É que eu não sei quem me bateu!". A criança, recordando um episódio ocorrido, representou uma grande preocupação sobre quem bateu nela quando tinha cerca de quatro anos de idade. Sua expectativa é que o juiz desvende esse acontecimento. Embora o juiz tenha os subsídios necessários com o apoio de outras áreas da ciência (Monteiro, 2010), há questões de impossibilidade da certeza, pois as opiniões técnicas podem também ser insuficientes (Santa Rosa et al., 2013). No desenho da solução, P7 representou a mãe, o pai e ele mesmo, sentados perante o juiz. O julgador está postado em sua tribuna com um martelo na mão para, ao som da ferramenta que bate sobre o móvel, acolhê-lo e oferecer uma resposta que espera acalmálo. "No Tribunal. Minha mãe, meu pai e 
eu aqui e aqui a minha mãe". A criança demonstra compreender adequadamente que a situação depende do julgamento do juiz (Santa Rosa et al., 2013).

Relativamente às expectativas sobre a mudança familiar com a decisão judicial, as crianças explicitam suas reflexões. P10: “(...) se a gente for querer voltar a morar com ela (mãe), ela vai voltar a brigar". P1: "Acho que eu posso ficar doente porque ela bebe muito, aí... (...) Porque o lugar não é bom também, porque ela sai muito. Ia deixar a gente sozinho... Chateado! Ela fica stressada... xinga muito!". P2: "Eu estou com medo de morar com o meu pai, porque eu quero morar com a minha mãe!’. As crianças conseguem identificar e indicar de forma precisa seus temores e confiam na escuta correta que os profissionais do contexto terão, para dizerem o que sentem. Parece que há uma concordância de que esperam ser ouvidas, protegidas e amparadas pela família, e que a Justiça poderá avaliar corretamente as melhores condições para que isso aconteça (Agulhas \& Anciães, 2014; Pereira \& Matos, 2011; Santa Rosa et al., 2014).

Os desenhos destacaram, com clareza, as preocupações e as soluções (Puviani, 2011) apresentadas pelas crianças no atendimento aos seus interesses. P9 desenhou um coração dividido ao meio com as partes esquerda e direita separadas, distanciadas uma da outra. As pontas que separam estão em forma de serra pontiaguda. Colocou fisionomias em cada metade. Do lado esquerdo, o olho está aberto representando a alegria, e a boca está com o canto esquerdo elevado, indicando o sorriso. Do lado direito, o olho está fechado representado por um estreito retângulo colorido de amarelo, deixando aparente o branco do papel. A boca, representada por um pequeno triângulo com a ponta voltada para o lado esquerdo, significando a tristeza. O coração tem as cores vermelha e amarela sobre o fundo azul claro do lado esquerdo e mais escurecido do lado direito. Nos traçados de P9, estão suas preocupações: “É, eu estou triste e aqui eu estou alegre. Triste com a minha mãe. Aqui são os olhos fechados e tristes. Com o meu pai”. A criança torna visível a sua ambivalência em relação a ter que fazer a escolha entre a mãe e o pai, que representa com um coração dividido ao meio (Agulhas \& Anciães, 2014). No problema, ela reconhece, na separação de seus pais, a divisão de si mesmo, ao desenhar o seu coração dividido. No desenho da solução, a criança fez uma grande nuvem cobrindo parte do sol, que aparece, acima dela, com traçado circular na cor amarela e raios coloridos de amarelo e vermelho. O arco-íris, do lado esquerdo da nuvem, mantém a alegria com o colorido, indicando que a chuva, que se pode entender como a tristeza da criança, passou e o sol está a brilhar, apesar de haver uma grande condensação de água que esconde parte do sol. Há uma casa e uma garagem ao lado. Os desenhos estão coloridos com traçados vermelho, amarelo, verde e marrom. Nota-se que as portas e as janelas estão fechadas. As duas figuras humanas que aparecem estão do lado de fora da casa e estão dispostas com proximidade. Embora haja um diálogo evidenciado pelos balões com textos descritos, as expressões faciais demonstram seriedade, pois as bocas são representadas apenas por um traçado. As figuras estão coloridas e em harmonia com os elementos que compõem o desenho.

Aqui ó, minha mãe tá longe e meu pai tá perto de casa, saiu agora. Aqui meu pai tá gritando: "Que tal a gente ser amigos?" Ela: "Sim!" Tá gritando de longe. (...) A casa que meu pai saiu e a 
garagem. Aqui são as nuvens e o arcoíris e o sol ensolarado. Meu pai, eu e meu irmão. E meus dois coelhinhos.

A criança consegue manifestar a solução que imagina ser possível de ocorrer. Sente-se confiante em externar seus pensamentos em espaço protegido, diante do profissional que o acolhe. Em seu desenho, representa os pais tornando-se amigos, por meio de uma proposição paterna que é aceita pela mãe. Descreve a composição da casa como um local seguro e acolhedor, evidenciando vida e movimento no ambiente, ao incluir dois pequenos animais de que gosta de cuidar e de brincar (Puviani, 2011).

As informações foram reveladas pela criança, integrando a fala e os desenhos de modo a comunicar seu mundo interno repleto de expressões não verbais e imagens que concretiza por meio dos traços do desenho (Andolfi, 1991; Puviani, 2011). Em suas reflexões, reconhece que o processo pode finalizar com decisões diferentes das que espera, porém percebe haver espaço para expressar suas preocupações e suas perspectivas sobre a solução para o impasse familiar no qual se insere (Cardoso \& Costa, 2014; Cashmore, 2011; Cashmore \& Parkinson, 2007; Cashmore \& Parkinson, 2009; Costa et al., 2009; Costa \& Miragem, 2012; Ferreira, 2008; Pereira \& Matos, 2008; Saywitz et al., 2010; van Nijnatten \& Jongen, 2011).

A discussão ocorrida tanto no núcleo 2 como no 3 indicou crianças envolvidas em conflitos sobre os quais têm perfeita noção das implicações de permanecerem, ou não, inseridos nesses ambientes que lhes trazem ansiedade e instabilidade. Mesmo que o drama vivido por uma criança tenha detalhes diferenciados, o que chama a atenção é a capacidade de ela perceber o papel e o potencial que o con- texto judicial tem sobre o restabelecimento de sua estabilidade.

\section{Considerações Finais}

Percebeu-se que a criança tem autonomia para informar, na Justiça, o que entende ser pertinente conforme o seu ponto de vista. Entretanto, percebe depender dos adultos para se sentir protegida e segura. A criança se considera atendida nos direitos de participação e de proteção no âmbito da disputa de guarda e regulamentação de visita, evidenciando necessitar de espaço acolhedor que lhe proporcione respeito e inclusão ao ser ouvida em seu ponto de vista (Birnbaum \& Saini, 2012; Cardoso \& Costa, 2014; Cashmore, 2011; Santa Rosa et al., 2014).

A criança reconhece, também, depender da decisão do juiz, que tem a intermediação de profissional especializado que a ouça, acolha e se disponibilize a ressaltar suas emoções e seus sentimentos nesse âmbito. Ela confia que o profissional encaminhará os seus pontos de vista para o juiz, que irá decidir de modo a garantir o atendimento de suas necessidades, que inevitavelmente envolve modificações na configuração familiar. Os resultados apontaram que a criança quer ser considerada e respeitada em suas necessidades individuais, que são próprias e únicas, (Birnbaum \& Saini, 2012). Ela também quer a valorização da qualidade de sua interação com a família e o reconhecimento das habilidades e das competências parentais (Ausloos, 1996; Fuhrmann \& Zibbel, 2012; Minuchin, 1990; Monteiro, 2010; Pereira \& Matos, 2011; Santa Rosa et al., 2013; Unicef, 1990). Os resultados demonstraram ainda que a Justiça, ao incluir o ponto de vista da criança, irá atendê-la em seus anseios, favorecendo e facilitando a aceitação das mudanças na família, decorrentes da decisão judicial, 
tornando os acordos mais viáveis e direcionados ao que importa para o seu saudável desenvolvimento (Birnbaum \& Saini, 2012; Cashmore, 2011; Graham \& Fitzgerald, 2010; Santa Rosa et al., 2013; Santa Rosa et al., 2014).

Para destacar as percepções da criança nesta pesquisa, decidiu-se entrevistá-la sem a presença de familiares. Essa opção, que pode ser vista como uma limitação do estudo, também pode ser considerada como um aspecto de grande valor, visto que diante dos membros da família, muitas expressões das crianças poderiam ser modificadas e/ou suprimidas. Um desafio não enfrentado nessa pesquisa foi a inclusão de crianças menores de 8 anos nessa temática, o que poderia levar a mudanças metodológicas para o alcance do objetivo. E ainda, por último, uma limitação consiste no número, relativamente reduzido, de crianças que foram entrevistadas.

\section{Referências}

Ackerman, M. J. (2006). Clinician's guide to child custody evaluations ( $3^{\text {rd }}$ ed.). New Jersey: John Wiley \& Sons.

Agulhas, R. \& Anciães, A. (2014). Casos práticos em psicologia forense: Enquadramento legal e avaliação pericial. Lisboa: Edições Sílabo.

Andolfi, M. (1991). Terapia familiar: un enfoque interaccional. Barcelona: Paidós.

Arantes, E. M. M. (2009). Proteção integral à criança e ao adolescente: Proteção versus autonomia? Psicologia Clínica, 21(2), 431-450.

http://dx.doi.org/10.1590/S0103-56652009000200012

Ausloos, G. (1996). A competência das famílias: Tempo, caos e processo. Lisboa: Climepsi.

Bauer, M. W., Gaskell, G., \& Allum, N. C. (2010). Qualidade, quantidade e interesses do conhecimento: Evitando confusões. In M. W. Bauer \& G. Gaskell (Eds.), Pesquisa qualitativa com texto, imagem e som: Um manual prático (pp. 17-36). Petrópolis: Vozes.

Birnbaum, R., Bala, N., \& Cyr, F. (2011). Children's experiences with family justice professionals in Ontario and Ohio. International Journal of Law, Policy and the Family, 25(3), 398-422.

http://dx.doi.org/10.1093/lawfam/ebr014

Birnbaum, R. \& Saini, M. (2012). A qualitative synthesis of children's participation in custody disputes. Research on Social Work Practice, 22(4), 400-409.

http://dx.doi.org/10.1177/1049731512442985

Brito, L., Ayres, L., \& Amendola, M. (2006). A escuta de crianças no sistema de justiça. Psicologia \& Sociedade, 18(3), 68-73.

http://dx.doi.org/10.1590/S0102-71822006000300010

Byrnes, P. (2011). Voices of children in the legal process. Journal of Family Studies, 17(1), 44-58.

http://dx.doi.org/10.5172/jfs.2011.17.1.44 
Cardoso, V. S. \& Costa, L. F. (2014). "Não me perguntem com quem eu quero ficar": A voz da criança e os avós no pedido de guarda judicial. Revista de Psicologia da IMED, 6(1), 58-64. http://dx.doi.org/10.18256/2175-5027/psico-imed.v6n1p58-64

Cashmore, J. (2011). Children's participation in family law decision-making: Theoretical approaches to understanding children's views. Children and Youth Services Review, 33(4), 515-520.

http://dx.doi.org/10.1016/j.childyouth.2010.05.008

Cashmore, J. \& Parkinson, P. (2008). Children's and parents' perceptions on children's participation in decision making after parental separation and divorce. Family Court Review, 46(1), 91-104.

http://dx.doi.org/10.1111/j.1744-1617.2007.00185.x

Cashmore, J. \& Parkinson, P. (2009). Children's participation in family law disputes: The views of children, parents, lawyers and counselors. Family Matters, 82, 15-21. Retrieved from http://ssrn.com/abstract=1471693

Costa, A. P. M. \& Miragem, F. B. (2012). A escuta e a participação de crianças e adolescentes em tomadas de decisão e o princípio do melhor interesse. In M. M. M. Costa, M. C. H. Leal, R. G. Leal, \& J. R. dos Reis (Eds.), As políticas públicas no constitucionalismo contemporâneo (Tomo 4, pp. 682-692). Santa Cruz do Sul/RS: EDUNISC. Retrieved from http://redenep.unisc.br/portal/upload/com_editora_livro/1364238825.pdf-page=22

Costa, L. F., Penso, M. A., Legnani, V. N., \& Sudbrack, M. F. O. (2009). As competências da psicologia jurídica na avaliação psicossocial de famílias em conflito. Psicologia \& Sociedade, 21(2), 233-241. http://dx.doi.org/10.1590/S0102-71822009000200010

Ferreira, M. T. F. (2008). A manifestação da vontade da criança na disputa judicial de guarda: Uma escuta psicanalítica (Dissertação de Mestrado, Centro de Ciências Humanas, Artes e Letras, Universidade Federal do Rio Grande do Norte, Natal, Brasil). Retrieved from http://repositorio.ufrn.br/handle/123456789/17429

Flick, U. (2009). Introdução à pesquisa qualitativa ( $3^{\mathrm{a}}$ ed.) Porto Alegre: Artmed.

Foot, W. L. (2011). How children's voices were heard "above the din" in family court proceedings in cases where there were allegations of child sexual abuse: The importance of judicial orientation and professional evidence in the discernment of the child's voice. Child Indicator Research, 4(4), 707-723. http://dx.doi.org/10.1007/s12187-011-9123-5

Fuhrmann, G. S. W. \& Zibbell, R. A. (2012). Evaluation for child custody. New York: Oxford.

Fundo das Nações Unidas para a Infância, Unicef. (1990). Convenção sobre os Direitos da Criança. Retrieved from http://www.unicef.pt/docs/pdf_publicacoes/convencao_direitos_crianca2004.pdf 
Graham, A. \& Fitzgerald, R. (2010). Exploring the promises and possibilities for children's participation in Family Relationship Centres. Family Matters, 84, 53-60. Retrieved from http://is.gd/ZQfgeT

Grisso, T. (2003). Evaluating competencies: Forensic assessments and instruments $\left(2^{\text {nd }}\right.$ ed.). New York: Plenum Publishers.

Huss, M. T. (2009). Forensic psychology: Research, clinical practice, and applications. United Kingdom: Wiley-Blackwell.

Johnston, J. R., Roseby, V., \& Kuehnle, K. (2009). In the name of the child: A developmental approach to understanding and helping children of conflicted and violent divorce ( $2^{\text {nd }}$ ed.). New York: Springer Publishing Company.

Kreuz, S. L. (2012). Direito à convivência familiar da criança e do adolescente: Direitos fundamentais, princípios constitucionais e alternativas ao acolhimento institucional. Porto Alegre: Juruá.

Minayo, M. C. (2014). O desafio do conhecimento: Pesquisa qualitativa em saúde $\left(14^{\text {th }}\right.$ ed.). São Paulo: Hucitec.

Minuchin, S. (1990). Famílias, funcionamento e tratamento. Porto Alegre: Artes Médicas.

Minuchin, S. \& Fishman, H. C. (1990). Técnicas de terapia familiar. Belo Horizonte: Artes Médicas.

Minuchin, S., Nichols, M. P., \& Lee, W-Y. (2009). Famílias e casais: Do sintoma ao sistema. Porto Alegre: Artes Médicas.

Monteiro, A. R. (2010). Direitos da criança: Era uma vez... Coimbra: Almedina.

Patel, S. H. \& Choate, L. H. (2014). Conducting child custody evaluations: Best practices for mental health counselors who are court-appointed as child custody evaluators. Journal of Mental Health Counseling, 36(1), 18-30.

http://dx.doi.org/10.17744/mehc.36.1.e00401wv7134w505

Pereira, A. L. \& Matos, M. (2008). As crianças, o divórcio e a regulamentação litigiosa do poder paternal. In C. Machado \& R. A. Gonçalves (Eds.), Violência e vítimas de crimes: Crianças (Vol. 2, pp. 275-299). Coimbra: Quarteto.

Pereira, A. L. \& Matos, M. (2011). Avaliação psicológica das responsabilidades parentais nos casos de separação e divórcio. In M. Matos, R. A. Gonçalves, \& C. Machado (Eds.), Manual de psicologia forense: Contextos práticos e desafios (pp. 311-347). Braga: Psiquilíbrios.

Ribeiro, R. (2010). A criança e o adolescente nos estudos psicossociais de Varas de Família. In I. Ghesti-Galvão \& E. C. B. Roque (Eds.), Aplicação da lei em uma perspectiva interprofissional: Direito, psicologia, psiquiatria, serviço social e ciências sociais na prática jurisdicional (pp. 271-282). Rio de Janeiro: Lumen Juris.

Puviani, V. (2011). O uso do desenho no trabalho clínico com crianças: Teoria e técnica. Belo Horizonte: ArteSã. 
Santa Rosa, B., Almeida, F., \& Corte-Real, F. (2014). A perícia médico-legal e o respeito pela autonomia da criança. In M. Paulino \& F. Almeida (Eds.), Psicologia, justiça e ciências forenses: Perspectivas atuais (pp. 161-178). Lisboa: Pactor.

Santa Rosa, B., Corte-Real, F., \& Vieira. D. N. (2013). O respeito pela autonomia da criança na regulação das responsabilidades parentais. Acta Medica Portuguesa, 26(6), 637-643. Retrieved from http://www.actamedicaportuguesa.com/revista/index.php/amp/article/view/4050

Saywitz, K., Camparo, L. B., \& Romanoff, A. (2010). Interviewing children in custody cases: Implications of research and policy for practice. Behavioral Sciences and the Law, 28(4), 542-562. http://dx.doi.org/10.1002/bsl.945

Skjørten, K. (2013). Children's voices in Norwegian custody cases. International Journal of Law, Policy and the Family 27(3), 289-309.

http://dx.doi.org/10.1093/lawfam/ebt011

Stahl, P. M. (2011). Conducting child custody evaluations: From basic to complex issues. California: Sage Publications.

van Nijnatten, C. \& Jongen, E. (2011). Professional conversations with children in divorcerelated child welfare inquiries. Childhood, 18(4), 540-555.

http://dx.doi.org/10.1177/0907568211398157 